\title{
Secondary oxalosis and sperm granuloma of the epididymis
}

\author{
J Coyne, L Al-Nakib, D Goldsmith, K O’Flynn
}

\author{
Department of \\ Histopathology \\ J Coyne \\ L Al-Nakib \\ Department of Renal \\ Medicine \\ D Goldsmith \\ Department of \\ Urology, University \\ Hospital of South \\ Manchester \\ K O'Flynn \\ Correspondence to: \\ Dr J Coyne, Department of \\ Histopathology, University \\ Hospital of South \\ Manchester, Nell Lane, \\ Didsbury, Manchester, \\ M20 8LR, UK. \\ Accepted for publication \\ 3 November 1993
}

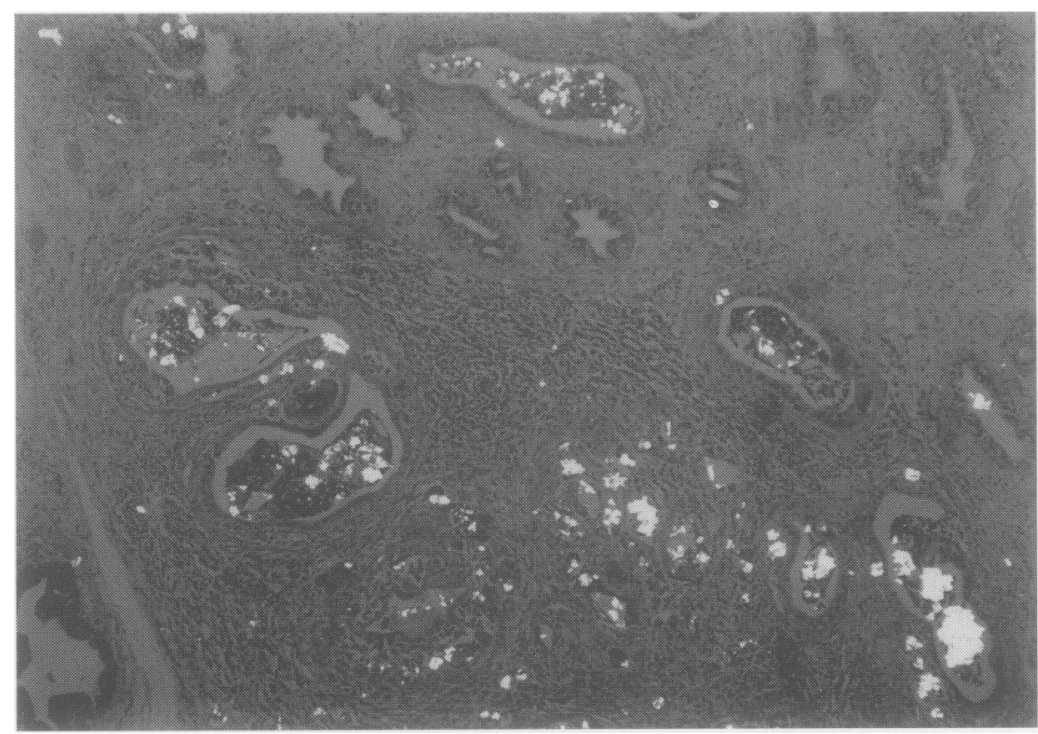

Figure 1 Birefringent calcium oxalate crystals within epididymal tubules.

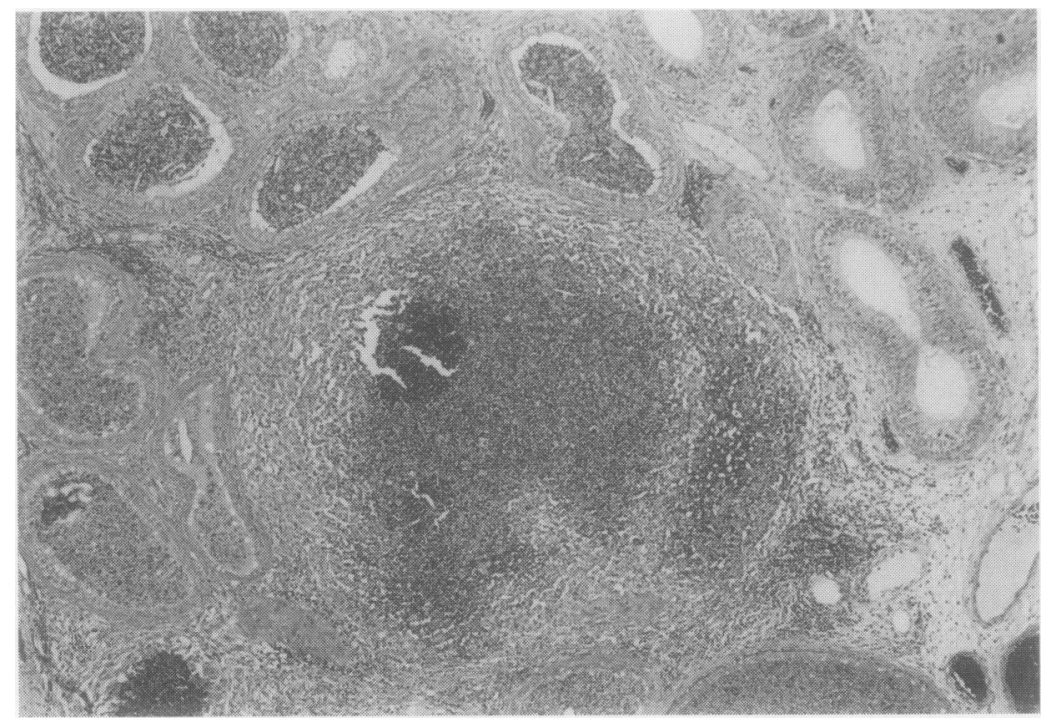

Figure 2 Sperm granuloma of epididymis.

\begin{abstract}
A 30 year old man with a 20 year history of chronic renal failure who presented with a testicular lesion is described. The lesional pathology, secondary oxalosis, and associated sperm granuloma of the epididymis was clinically considered to be an intrascrotal tumour. The oxalate crystal deposition was present within the rete testis, the ductuli efferentes, and the epididymis along with sperm granulomata. This seems to be a rare complication of secondary oxalosis associated
\end{abstract}


cytoplasm. In places the interstitial fibrosis projected into the tubules of the ductuli efferentes testis and epididymis as broad obstructing papillary structures. Haemosiderin deposition was not a feature.

The testis showed extensive, focal tubular atrophy and fibrosis with the rest of the tubules showing mild hypospermatogenesis. The body and tail of the epididymis showed extremely dilated epididymal tubules containing proteinaceous material and occasional spermatozoa.

\section{Discussion}

Chronic renal failure may produce hyperoxalaemia and secondary oxalosis due to decreased oxalate excretion with the tissue deposition (oxalosis) typically occurring within the kidney, although other organs may also be involved. ${ }^{1-3}$ Furthermore, deposition of calcium oxalate crystals within the rete testis and ductuli efferentes of patients with chronic renal failure has been described under the descriptive notation of acquired cystic transformation of the rete testis. ${ }^{4}$ Although showing cystic dilatation of the rete testis, this case differs in several respects including the clinical presentation with a palpable, intrascrotal lesion, haematospermia (which was cured by surgery), and a small associated hydrocele. Also, the histological involvement was more extensive producing prominent epididymal oxalosis and epididymal spermatic granuloma formation. Direct damage to the epididymal tubular epithelium and basement membrane, with or without tubular obstruction and distension caused by interstitial fibrosis, are mechanisms for spermatic granuloma formation. To the best of our knowledge, the combination of calcium oxalosis and spermatic granulomas of the epididymis has not been reported before.

We thank Dr Alan Curry for the photomicrographs and Mrs Linda Garstang for excellent secretarial assistance.

1 Salyer WR, Keren D. Oxalosis as a complication of chronic renal failure. Kidney Int 1973;4:61-6.

2 Cuppage FE, Chonko AM. Urate and uric acid nephropathy, cystinosis and oxalosis. In: Tisher CC, Brenner BM, eds. Renal pathology. Philadelphia: JB Lippincott, BM, eds. Renal
1989:1351-7.

3 Chaplin AJ. Histopathological occurrence and characterisation of calcium oxalate: a review. $\mathcal{F}$ Clin Pathol 1977; 30:800-11.

4 Nistal M, Santamaria L, Paniagua R. Acquired cystic transformation of the rete testis secondary to renal failure. Hum Pathol 1989;20:1065-70.

\title{
Polycythaemia rubra vera transforming to acute lymphoblastic leukaemia with a common immunophenotype
}

\author{
J R Neilson, W N Patton, M D Williams, E E Mayne, B J Boughton
}

\author{
Department of \\ Haematology, Queen \\ Elizabeth Hospital, \\ Birmingham \\ J R Neilson \\ W N Patton \\ M D Williams \\ B J Boughton \\ Department of \\ Haematology, Royal \\ Victoria Hospital, \\ Belfast \\ E E Mayne \\ Correspondence to: \\ Dr J R Neilson, Department \\ of Haematology, \\ of Haematology, \\ Birmingham Heartlands
Hospital, Bordesley Green \\ East, Birmingham. \\ Accepted for publication \\ 25 November 1993
}

\begin{abstract}
Lymphoblastic transformation of polycythaemia rubra vera is an extremely rare phenomenon. A case of a 76 year old man with polycythaemia rubra vera who developed acute lymphoblastic leukaemia (ALL) 16 years after his initial diagnosis is reported. Membrane markers showed a CD10 positive (common ALL) immunophenotype. To our knowledge this association has not been previously recorded. The rare occurrence of ALL in polycythaemia rubra vera may indicate that in a minority of patients clonal expansion of an abnormal pluripotent haemopoetic stem cell is responsible for the polycythaemia rubra vera disease phenotype.
\end{abstract}

\section{(F Clin Pathol 1994;47:471-472)}

The transformation of polycythaemia rubra vera to myelofibrosis or acute myeloblastic leukaemia is well recognised but the transfor- mation of polycythaemia rubra vera to acute lymphoblastic leukaemia (ALL) is an extremely rare phenomenon. We report a case of polycythaemia rubra vera who transformed into ALL with a CD10 positive immunophenotype, to our knowledge, an association not previously recorded.

\section{Case report}

A 76 year old man presented with polycythaemia rubra vera in 1974 . His haemoglobin concentration was $230 \mathrm{~g} / \mathrm{l}$, white cell count $11.2 \times 10^{9} / 1$, and platelet count $260 \times$ $10^{\circ} / 1$. Splenomegaly $(3 \mathrm{~cm})$ was present and his red cell mass was raised at $60.6 \mathrm{ml} / \mathrm{kg}$. He was initially treated with venesection and aspirin. Intermittent low dose busulphan treatment was started in 1979 for increasing splenomegaly. Treatment with intermittent venesection and low dose busulphan was continued until the development of deteriorating pancytopenia (haemoglobin concentration 72 $\mathrm{g} / \mathrm{l}$, white cell count $2.5 \times 10^{9} / 1$, platelet count 